\title{
Laser Cleaning of Oxidised Metallic Materials: Role of the Optical Properties of the Oxide Films.
}

\author{
P. Pasquet ${ }^{1}$, P. Psyllaki ${ }^{1}$, R. Oltra ${ }^{1}$, J.P. Boquillon ${ }^{2}$, \\ P. Leiderer ${ }^{3}$, J. Boneberg ${ }^{3}$, S. Joiret ${ }^{4}$, A. Hugot-Le Goff ${ }^{4}$, \\ ${ }^{1}$ L.R.R.S., UMR 5613 CNRS, Université de Bourgogne, B.P. 47 870, 21078 Dijon, France \\ ${ }^{2}$ L.P.U.B., UMR 5027 CNRS, Université de Bourgogne, B.P. 47 870, 21078 Dijon, France \\ ${ }^{3}$ Universität Konstanz, Zentrum für Moderne Optik Konstanz, 78457 Konstanz, Germany \\ ${ }^{4}$ L.P.L.E., UPR 15 CNRS, Université P. et M. Curie, 75252 Paris, France
}

\begin{abstract}
In the present work, the effects of nanosecond pulsed laser irradiation on oxidised metallic surfaces were investigated, in order to estimate the possibility of using laser techniques for cleaning applications.

After oxidation, the oxide layer developed on the metallic surfaces depends on the composition of the substrate and also on oxidation conditions. In this study a modelling system: pure $\mathrm{Fe}$ oxidised at $500^{\circ} \mathrm{C}$, has been investigated.

The influence of the optical properties of the oxide films on the removal mechanisms and the cleaning efficiency of the laser technique was illustrated by performing specific electrochemical treatments.
\end{abstract}

Keywords: Laser cleaning, Oxide removal, RAMAN, Optical properties

\section{INTRODUCTION}

In recent years, an increasing interest on the use of laser irradiation for surface cleaning is observed. Compared to the conventional methods of surface cleaning, laser technique, -especially, when combined with an optical fibre [1],- offers significant advantages, such as: localised treatment, remote application (from distance), suitable for treatment of pieces of complicated geometry, etc. However, the vast advance in laser technology, the often obscure interaction between photons and material, as well as the need for the removal of a thin layer without affecting the underlying material, complicate the choice of the appropriate laser source (solid- or gas-state laser, wavelength) and the operational parameters (energy density, continuous/ pulsed mode, speed/ pulse duration, etc).

Despite the above mentioned problems, the relatively recent technique of laser cleaning has already found successful application in many domains:

- in microelectronics, for the removal of adherent particles from semiconductors [2,3],

- in aerospace industry, for the removal of paint from aircraft [4],

- in art conservation, for the removal of varnish, overpaints or corrosion layers from a great variety of materials, such as wood, stone, etc [5,6].

The aim of this study, was to understand the role of the optical properties of the contaminant layer on the laser cleaning of an oxidised surface. Using a modelling system it will be demonstrated that electrolytical hydrogen charging of the iron oxide layer is responsible for change in optical properties of the iron oxide that makes possible its removal.

\section{EXPERIMENTAL}

Pure iron $(99.8 \%)$ substrates were polished with $1 \mu \mathrm{m}$ diamond powder and rinsed in an ultrasonic bath of alcohol and acetone. Then they were placed in a furnace at $500^{\circ} \mathrm{C}$ and $10^{-5}$ mbar residual pressure during $5 \mathrm{~h}$. After that they were

\footnotetext{
* Correspondence: E-mail: oltra@u-bourgogne.fr; http://www.u-bourgogne.fr/REACTIVITE/TMR; Telephone: 333 80396162; Fax: 33380396132
} 
oxidised at $500^{\circ} \mathrm{C}$, for $48 \mathrm{~h}$ with an air residual pressure of 10 mbar. $\mathrm{A} \mathrm{Fe}_{3} \mathrm{O}_{4}$ surface layer with a thickness of $1000 \mathrm{~nm} \pm$ $100 \mathrm{~nm}$ was obtained.

The cleaning has been made in three different conditions, in air for reference, without and with electrochemical control. The irradiation was performed by means of a Nd:YAG laser ( $\lambda=532 \mathrm{~nm} / \tau=7 \mathrm{~ns}$, FWHM or $\lambda=1064 \mathrm{~nm} / \tau=14 \mathrm{~ns}$, FWHM). Each irradiated area received several laser pulses. Pulse energy densities in the $380-700 \mathrm{~mJ} / \mathrm{cm}^{2}$ ranges were used to irradiate the sample.

For the experiment with electrochemical control, the samples were placed in an electrochemical cell. The electrolyte used, was a solution of $\mathrm{H}_{3} \mathrm{BO}_{3}(0.05 \mathrm{M})$ and $\mathrm{Na}_{2} \mathrm{~B}_{4} \mathrm{O}_{7}, 10 \mathrm{H}_{2} \mathrm{O}(0.075 \mathrm{M})$ at $\mathrm{pH}=9.2$. A cathodic polarisation $(\mathrm{V}=-1.5 \mathrm{~V} / \mathrm{SCE})$ was applied from 1 to 40 minutes.

The optical study has been made by a spectrometer (Polytec) in combination with a microscope. The wavelengths used were between 450 - $900 \mathrm{~nm}$. Before and after the laser irradiation the samples were characterised by X-ray reflectometry, Scanning Electron Microscopy (SEM), Atomic Force Microscopy (AFM) and laser profilometry.

RAMAN spectroscopy was employed to characterise the structural changes induced by the cathodic potential applied before laser exposure. A particular interest was the removal mechanism and the reversibility of the change induced in the oxide layer after applying the potential.

\section{RESULTS}

In the case of specimens irradiated in air or in basic aqueous solution without previous polarisation, their laser treatment resulted in the melting of the oxide layer, but not its removal (Figure 1). In the case specimens irradiated in basic aqueous solution after their cathodic polarisation, laser treatment induced the removal of the oxide layer without melting (Figure 2).
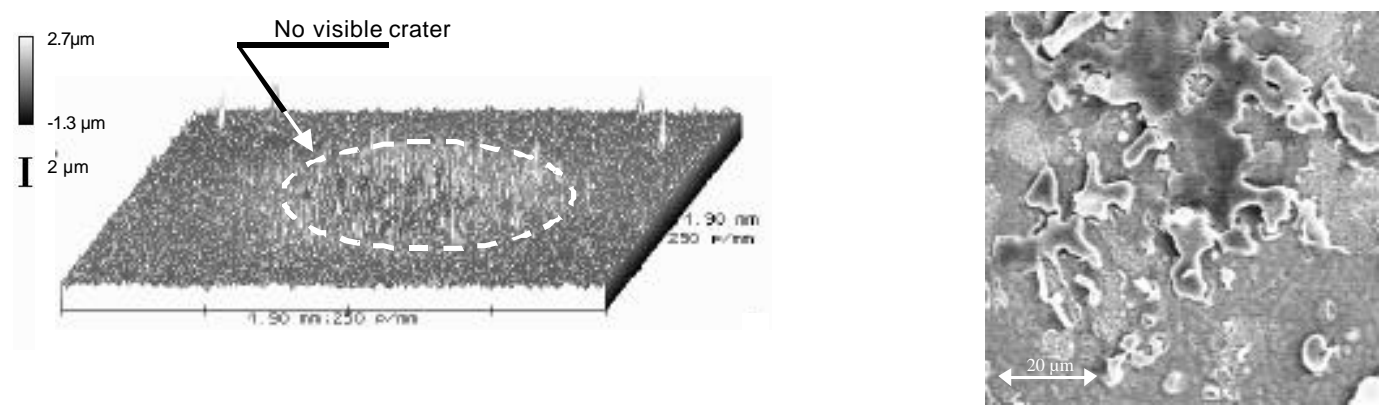

(a)

Figure 1. Feature of the irradiated area at $570 \mathrm{~mJ} / \mathrm{cm}^{2}$, in air $((\lambda=532 \mathrm{~nm} / \tau=7 \mathrm{~ns})$

(a) Laser profilometry : no removal of the oxide layer.

(b) S.E.M. showing partial melting of the oxide layer.

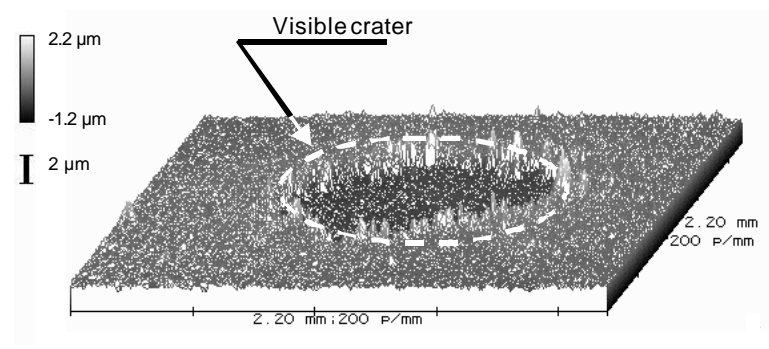

(a)

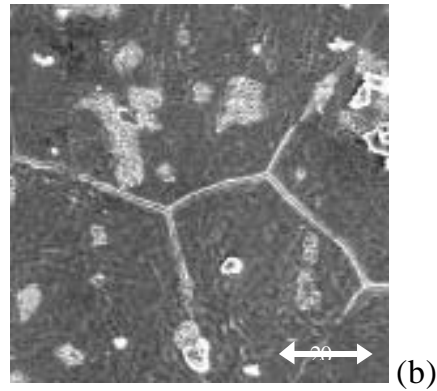

Figure 2. Feature of the irradiated area at $570 \mathrm{~mJ} / \mathrm{cm}^{2}$, in basic aqueous solution with previous polarisation of the substrate

(a) Laser profilometry: removal of the oxide layer.

(b) S.E.M. showing no melting of the oxide layer and grain boundaries of the cleaned substrate. 
The optical properties of the surface layer were determined by optical spectrometry at normal incidence, for wavelengths in the range of 450-1100 $\mathrm{nm}$. In order to quantify the changes of the refractive index due to the electrochemical control imposed, a theoretical model permitting the calculation of the real and imaginary part of refractive index of the oxide layer was developed [7].

These theoretical considerations allow to determine the optical properties (n, k) of the oxide layer after 40 minutes of an electrochemical control as function of the wavelength. The real part is not largely modified (10\%), but the imaginary part is reduced by a factor 10 leading to an important increase of the optical absorption length (Figure 3 ). The reason for this huge change of $\mathrm{k}$ is not clear at this moment. A possible explanation assumes that diffusion of atomic hydrogen into the oxide takes place, and is trapped in the oxide film.

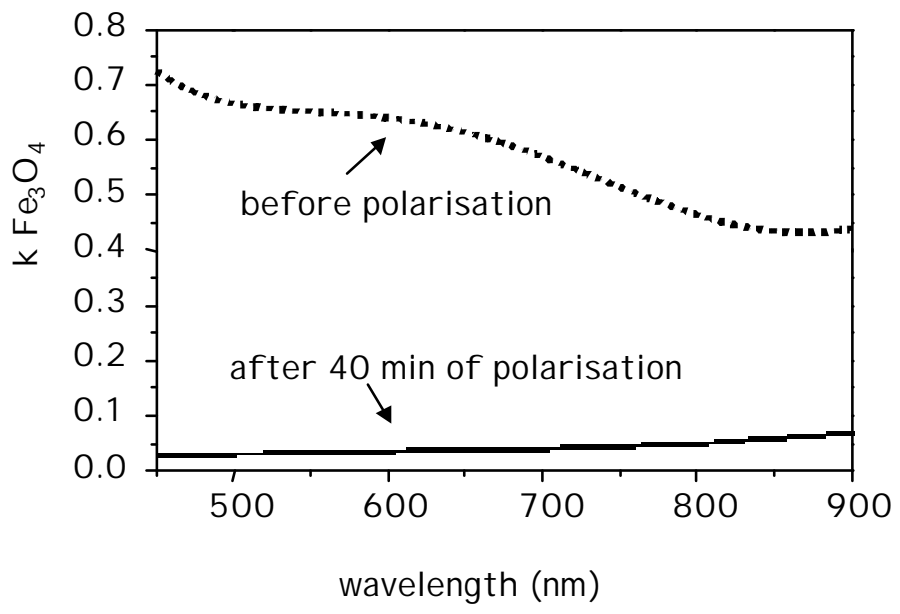

Figure 3. Calculated values of $\mathrm{k}$ of the $\mathrm{Fe}_{3} \mathrm{O}_{4}$ layer before and after polarisation.
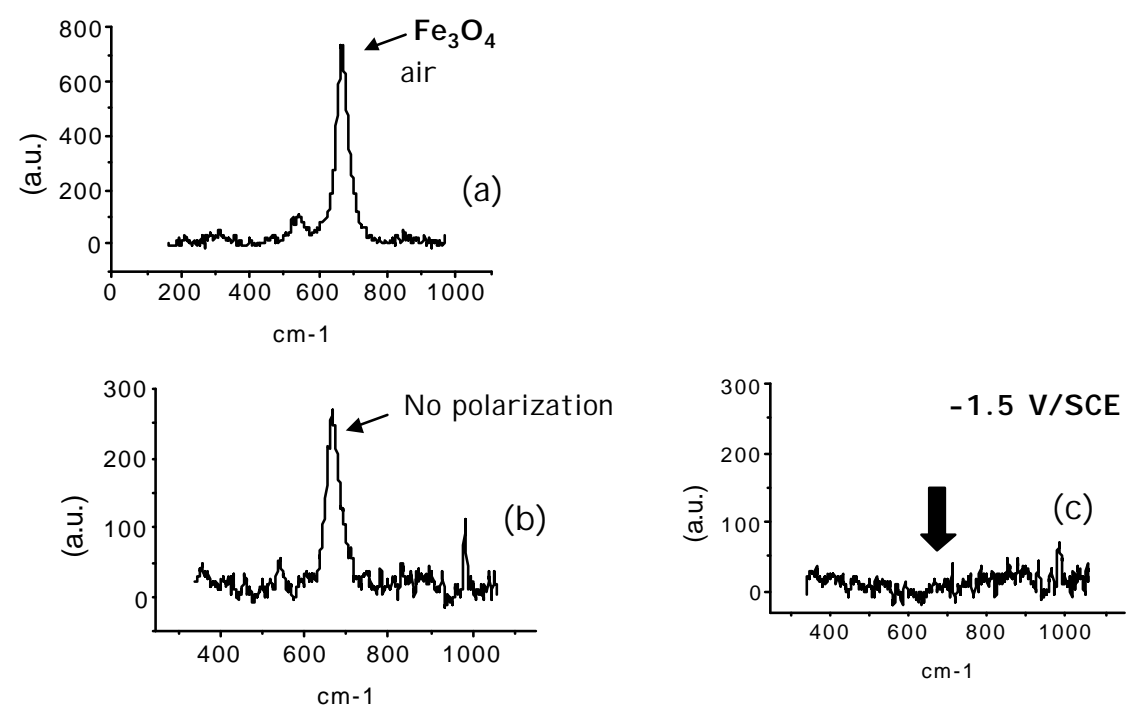

Figure 4 - RAMAN spectra obtained on oxidised iron samples:

(a) - in air

(b) - in electrolyte without polarisation

(c) - in electrolyte after 40mn polarisation 
In order to determine whether these modifications are chemical and/or structural in nature, we performed RAMAN analysis. Figure 4 shows the RAMAN spectra obtained for the as-grown oxide layer without any treatment, after immersion in the borate solution before and after applying the cathodic potential and in air several hours after the electrochemical treatment. The RAMAN spectra of the oxide layer in air prior to any treatment exhibits an intense and well resolved peak at $675 \mathrm{~cm}^{-1}$ related to $\mathrm{Fe}_{3} \mathrm{O}_{4}$ which is the major component of the layer, proving that we are dealing with a well crystallised oxide. In the borate solution without applying the cathodic potential neither position, nor intensity of the $\mathrm{Fe}_{3} \mathrm{O}_{4}$ peak are modified.

One can note however that the background signal increases with increasing frequency due to the electrolyte. After the electrochemical treatment (i.e., -1.5 V/SCE during $40 \mathrm{~min}$.), it can be seen the peak related to $\mathrm{Fe}_{3} \mathrm{O}_{4}$ cannot be detected (Figure 4c). In contrast, the RAMAN analysis of the same sample let in air during few hours shows that the layer has returned to its initial structure, proving that the process is reversible.

These observations confirmed that the hydrogen formation results from the value of the applied cathodic potential that is in the domain of water electrolysis for which $\mathrm{H}^{+}$ions are reduced in atomic hydrogen which diffuses and affects the optical properties of the oxide layer. The reason for the differences in the cleaning process confirmed previous results [8]: before polarisation the laser pulses energy is deposited at the surface layer and the oxide is melted. After polarisation, the energy is deposited in the volume of the oxide layer which leads to a complete removal of the oxide. This results in a complete change of the laser mechanism for removal which can be summarised as follows:

- In absence of polarisation, the film is absorbent and the optical penetration of the beam can be calculated to be $1 / \alpha \sim 70 \mathrm{~nm}$ leading to the localised absorption of the laser energy at the outer interface oxide-electrolyte. In this case the oxide film is melted and not completely removed by only one shot.

- After cathodic polarisation, the laser beam penetration becomes $1 / \alpha \sim 900 \mathrm{~nm}$ which is close to the thickness of the oxide layer. In this case a significant part of the incident light heat the iron substrate that could induce a thermoelastic deformation of the metallic substrate leading to the spallation of the film following the mechanism described for other transparent oxide films [9]. In this case there is a de-bonding of the oxide film from the metallic substrate which can be cleaned without any kind of mechanical damage as shown in Figure $2 \mathrm{~b}$.

\section{CONCLUSION}

The effect of an electrochemical treatment on the efficiency of the laser removal of an oxide film has been demonstrated. The cathodic polarisation is responsible for a large increase of the optical penetration of the laser beam leading to a thermoelastic deformation of the metallic substrate which induce the mechanical debonding of the oxide film without any kind of damage to the metallic substrate. This study illustrate the basic role of the optical properties of the layer to be removed upon the laser cleaning mechanisms.

\section{Acknowledgements:}

P. Psyllaki and P. Pasquet were supported by European programme TMR ERB FMRX CT098-0188 "Laser Cleaning"

\section{REFERENCES}

1. J.P. Boquillon, P. Bresson, H. Berger, "Procédé de nettoyage de surface par laser impulsionnel", Patents France ${ }^{\circ}$ 8900496, USA n ${ }^{\circ}$ 5151134, European n 904001229.

2. P. Leiderer, J. Boneberg, V. Dobler, M. Mosbacher, H.-J. Münzer, N. Chaoui, J. Siegel, J. Solis, C.N. Afonso, T. Fourrier, G. Schrems, D. Bäuerle "Laser-induced Particle Removal from Silicon Wafers", Proceedings of SPIE, High Power Laser Ablation III, SPIE 4065, pp.249-259, 2000.

3. W.Zapka, W.Ziemlich and A.C. Tam, " Efficient pulsed laser removal of $0.2 \mu \mathrm{m}$ sized particles from a solid surface", Appl. Phys. Lett. 58, pp. 2217-2219, 1991.

4. J.S. Foley and P.A.Barone, "Automated laser paint stripping", Metal Finishing, pp. 48-50, May 1992.

5. S. Georgiou, V. Zafiropoulos, D. Anglos, C. Balas, V. Tornari, C. Fotakis," Excimer laser restoration of painted artworks: procedures, mechanisms and effects", Appl. Surf. Sci., 127-129, pp. 738-745, 1998.

6. G. Sabatini, M. Giamello, R. Pini, S. Siano, R. Salimbeni, "Laser cleaning methodologies for stone façades and monuments: laboratory analyses on lithotypes of Siena architecture", Journal of Cultural Heritage, 1, pp. S9-S19, 2000.

7. P. Pasquet, R. Del Coso, J. Boneberg, P. Leiderer, R. Oltra, J.P. Boquillon, "Laser cleaning of oxide iron layer : Efficiency enhancement due to electrochemical induced absorptivity change", Appl. Phys. A 69, pp.727-730, 1999.

8. R. Oltra, O. Yavas and O. Kerrec, "Enhancement of pulsed laser removal of metal oxides by electrochemical control", Appl. Phys. A 64, pp. 321-327, 1996.

9. P.Psyllaki, R.Oltra, "Preliminary study on the laser cleaning of stainless steels after high temperature oxidation", Materials Science and Engineering A, 282, p.145-152, 2000 